\title{
Fallo de la XII edición del premio Vida y Salud de Relatos
}

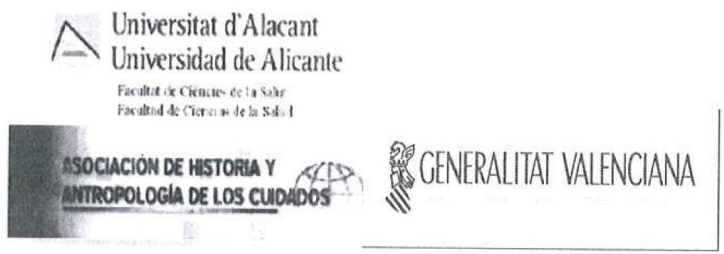

Alicante, 11 de junio de 2019

La XII edición del premio Vida y Salud de Narrativa, se ha convocado este año con el lema: "Violencia de género, mutilación genital femenina y cuidados de salud". Este premio ha contado con el patrocinio $y$ organización de la Asociación de Historia y Antropología de los Cuidados, la Facultad de Ciencias de la Salud y la Consejería de Sanidad de la Generalitat Valenciana. El jurado del XII Premio Vida y Salud de Narrativa integrado por su Presidente: José Antonio Hurtado Sánchez. Vocales: Ana Lucía Noreña Peña, Ana I. Gutiérrez Hervás, Carmen Solano Ruíz, Elena Andina Díaz. Secretario: José Siles González.

Esta edición ha obtenido una gran participación sobre todo en la modalidad absoluta (232 relatos) procedentes de diversos países: 139 relatos se han enviado desde más de veinte países latinoamericanos (32 Argentina, 29 Colombia, 18 Cuba, 12 Chile, 12 Méjico, 8, Venezuela, 7 Uruguay, 3 Panamá, 5 Perú, 3
Paraguay, 3 Puerto Rico, 2 Guatemala, 2 Ecuador, 2 Bolivia, 1 Honduras, 1 Nicaragua, Brasil 1, etc.). La procedencia del resto es europea (1 Francia y el resto de diversas provincias de España). En la modalidad estudiantes profesionales ha habido una baja participación, sobre todo si lo comparamos con ediciones anteriores del certamen.

Fallo: En Alicante, siendo las 11,15 horas del martes 11 de junio del año dos mil diecinueve, reunido el Jurado se ha decidido, tras la valoración de los relatos finalistas, conceder los siguientes premios:

-El ganador del premio absoluto (modalidad abierta) corresponde por mayoría de los miembros del jurado en segunda ronda al relato número 200 presentado bajo el título de "Elsabet" y que tras la apertura de la plica correspondiente es autoría de D. G. Felipe Grisolía Ambrosini. Felipe Grisolía Ambrosini (1944) es arquitecto por la Universidad de Buenos Aires, diseñador gráfico y tiene una dilatada 
trayectoria literaria.

-En la modalidad "profesionales estudiantes" el premio ha sido declarado desierto.

José A. Jurado Sánchez (Presidente)

Vocales: Ana L. Noreña Peña

Ana I. Gutiérrez Hervás

Carmen Solano Ruíz

Elena Andina Díaz

Secretario: José Siles González
Tal como estipulan las bases, el relato premiado será publicado en la revista Cultura de los Cuidados y se valorará, previa consulta con los autores, la publicación de un libro con los relatos finalistas.

\section{Finalistas XII certamen Vida y Salud de Narrativa:}

203.- EI Vuelo de los lepidópteros

200.- Elsabet

1.- Mi papá quería a mi mamá

92. - Un trabajo bien hecho

143.- Historia en el armario.

20.- La puerta del infierno

24.- Por cultura

197.- Demonios

191.-Kioni

199.-Mujer completa 